\title{
New perspectives on learning
}

Distance experiential education practices: sharing and cross-pollination of traditional university-type and former techikon-type work-integrated learning practices

Keith Richmond (editor)

University of South Africa, 2006

ISBN 1-86888-383-3

Reviewed by Mary Grosser

North-West University

This volume contains papers delivered at an internal seminar held at Unisa. The focus is on the importance of work-integrated or distance experiential learning, an important criterion identified by the Higher Education Quality Committee (HEQC) of the Council on Higher Education $(\mathrm{CHE})$ for institutional audits and programme accreditation. The collection shares a variety of experiences and current practices from different fields of study at Unisa, namely Human Sciences, Health Sciences, Social Sciences, Education Sciences, Library and Information Studies, Economic and Management Sciences, Information Technology, Engineering, Animal Health and Horticulture.

The papers offer readers exposure to various forms of work-based learning education practices. All the papers highlight the importance of a well-managed system of features crucial to the success of work-based learning. In essence, the following aspects are highlighted. The curriculum design should be carefully constructed around outcomes and should consist of theoretical and practical components. In order to guarantee the success of work-based learning student support, in the form of audio-conferencing, e-mail, CD-ROM, interactive television, tutorial letters, study guides and workbooks providing detailed instructions, should not be neglected. All the contributions highlight the value of suitable supervisors, mentors or preceptors at the site of learning. These should be experienced people who should take active roles in accompanying learners to integrate knowledge and practice, keep in constant communication with the university lecturer 
regarding learner progress, and act as co-evaluators of learners' work. The authors are in accord that continuous assessment (formative and summative) as well as interactive assessment of learner progress during work-based learning is of vital importance.

The presentations are clear about the fact that work-based learning poses numerous challenges and barriers. Among others, finding appropriately trained supervisors, travelling to the sites of learning, appropriate learner support, commitment of supervisors, stimulating learners' self-activities and constantly reviewing and adjusting the curricula to meet current and future needs are mentioned. For certain models of work-based learning (laboratory sessions, practical sessions and group work) students are often unprepared, do not turn up for their sessions or sometimes delay group work and feedback. This obstructs the effectiveness of the work-based learning.

Apart from the challenges and barriers, advantages of work-based learning are also addressed. Advantages of work-based learning are evident in all the mentioned fields of learning. Establishing the link between theory and practice, exposure to the working environment, career relevance, inculcation of professional values and work ethics, developing confidence and skills, and establishing partnerships with business and industry are but a few mentioned.

This is a coherent set of presentations in which the practice, relevance, limitations and advantages of work-based learning in a variety of contexts are considered. The more closely one looks at the headline concepts in this book the more transparent it becomes that this is the way in which learning should take place. Learning is widely acknowledged to have social, affective and cognitive aspects, and work-based learning supports this notion of learning.

For readers interested in knowing what it is like to conduct workbased learning, some useful snippets of information may be gleaned from the relevant presentations. However, in each case, one is left wondering how successful the particular approach is. The book might have been improved by an additional evaluation of the various workbased learning models discussed, based on a measurement of learning gains achieved by a work-based model in comparison to the learning gains achieved by the previous classroom-based models. Only one model, namely that of Library and Information Studies, evaluates the learning gains achieved by work-based learning.

Although the outcome was in favour of work-based learning, it is not clear whether the desired link between theory and practice had been established and whether professional values and ethics had been inculcated. It would be interesting to see whether the link between theory and practice, and the inculcation of professional values and ethics, which are obviously some of the main outcomes of work-based 
learning, could be achieved with the other models. Furthermore, the volume may have benefited from a discussion of some international perspectives on the field, to provide the reader with an opportunity to appreciate the breadth and scope of interest in this field. Nonetheless, the volume offers the reader a rich and varied taste of the field of current work-based education practices at Unisa as well as expertise from which to draw on. 